\title{
HIV-1 Tat enhances replicative potential of human oral keratinocytes harboring HPV-16 genome
}

\author{
REUBEN H. KIM ${ }^{1-3}$, JI MIN YOCHIM ${ }^{1}$, MO K. KANG ${ }^{1-3}$, KI-HYUK SHIN ${ }^{1-3}$, \\ RUSSELL CHRISTENSEN $^{1}$ and NO-HEE PARK ${ }^{1-4}$ \\ ${ }^{1}$ UCLA School of Dentistry; ${ }^{2}$ UCLA Dental Research Institute; ${ }^{3}$ UCLA Jonsson Comprehensive Cancer Center; \\ ${ }^{4}$ David Geffen School of Medicine at UCLA, Los Angeles, CA 90095, USA
}

Received June 13, 2008; Accepted July 24, 2008

DOI: 10.3892/ijo_00000064

\begin{abstract}
Introducing highly active antiretroviral therapy (HAART) has significantly decreased the morbidity and mortality in human immunodeficiency virus-positive $\left(\mathrm{HIV}^{+}\right)$ individuals by decreasing the viral loads and increasing the CD4 ${ }^{+}$T-cell counts. Subsequently, the occurrence of many HIV-associated diseases has been dramatically declined except human papillomavirus (HPV)-associated lesions. Such notion suggests that immune response is not a major determinant, and that the direct interaction between HIV and HPV may be involved in the HPV-associated pathogenesis. In the current study, we investigated whether HIV plays a direct role in HPV-associated oral carcinogenesis by using HIV-1 transactivator protein (Tat), which is known to have oncogenic properties. We found that HIV-1 Tat not only increased the expression of HPV-16 E6 and E7 oncogenes in human oral keratinocytes harboring the HPV type-16 genome (HOK-16B), but also notably enhanced the proliferative capacity of the cells in vitro. Moreover, HOK-16B cells expressing HIV-1 Tat was capable of inducing cystic nodules in nude mice, while the control HOK-16B cells failed to produce nodules in the mice. Our results indicate that HIV could play a role in the HPV-associated pathogenesis by exerting oncogenic stimulus via Tat protein.
\end{abstract}

\section{Introduction}

It is widely known that the prevalence and incidence of human papillomavirus (HPV) infection and HPV-associated diseases including squamous cell carcinoma are greater in human immunodeficiency virus-positive $\left(\mathrm{HIV}^{+}\right)$individuals when compared to $\mathrm{HIV}^{-}$individuals $(1,2)$. In $\mathrm{HIV}^{+}$individuals, studies described increased incidence and prevalence of both anal/cervical HPV infection and invasive anal/cervical cancers

Correspondence to: Dr No-Hee Park, UCLA School of Dentistry, CHS 53-038, 10833 Le Conte Ave., Los Angeles, CA 90095-1668, USA

E-mail:nhpark@dentistry.ucla.edu

Key words: HIV-1 Tat, HPV-16, tumorigenesis, normal human oral keratinocytes as compared to HIV- individuals $(3,4)$. Similarly, several reports suggest increased occurrence of $\mathrm{HPV}$-associated oral squamous cell carcinoma (OSCC) in $\mathrm{HIV}^{+}$individuals (5-9).

Early observations suggest that the prevalent tumor incidences in $\mathrm{HIV}^{+}$individuals are primarily attributed to the defective tumor surveillance mechanisms associated with immunodeficiency. However, $\mathrm{HIV}^{+}$individuals with no sign of acquired immunodeficience syndrome (AIDS) and with normal $\mathrm{CD}^{+}{ }^{+} \mathrm{T}$-cell count still exhibited elevated incidence of rapidly progressing, refractory cervical intraepithelial neoplasia (10), indicating that immunosuppression alone cannot account for the increased occurrence of HPVassociated lesions and tumor development in $\mathrm{HIV}^{+}$ individuals.

HIV transactivator protein (Tat) plays a direct role in the tumor pathogenesis of HIV. Tat is a $14-15 \mathrm{kDa}$ protein essential for HIV transcription and replication (11). Tat gene is composed of two exons; exon 1 contains amino acids 1-72, and exon 2 contains amino acids 73-101. Tat protein is frequently expressed in variant forms, which range in length from 72 amino acids (one-exon Tat) to 86-101 amino acids (two-exon Tat) (12). Mutation analyses of Tat have revealed the presence of multiple functional domains in the first exon of Tat (13). The N-terminal domain contains transactivation domain which is composed of the acidic, cysteine-rich, and conserved RKGLGI domain. The basic, arginine-rich domain (RKKRRQRRR) is important for nuclear localization and protein transduction activities (14). Tat is also an RNA binding protein, and the C-terminus of the first exon was mapped for this activity (15). Several studies have suggested that the second exon of Tat is important for T-cell activation (16) and for induction of apoptosis by inhibiting manganese superoxide dismutase (Mn-SOD) activity (17). These studies indicate that Tat protein elicits pleiotropic effects, which are essential for productive infection of HIV and are capable of disturbing normal cellular homeostasis.

Tat is produced in the early phase of infection without being integrated into the host genome (18). Tat can be secreted out of the cells and can enter the neighboring cells, eliciting important biological activities. Tat targets the primary 'gate keepers' of the mammalian genome, i.e., p53 and pRb2/p130 (19-21), and abrogates the G1 checkpoint mechanism in response to DNA damage (22). Direct evidence to support 
the oncogenic property of Tat is found in Tat-transgenic mice, which shows higher incidence of spontaneous and carcinogeninduced tumor development $(23,24)$. Therefore, HIV may enhance the tumorigenic potential of HPV, possibly through Tat.

Previously we found that 'high risk' HPV disrupts the cell cycle control and induces genetic instability in normal human oral keratinocytes (NHOK), which can be immortalized by HPV DNA (25). However, HPV alone failed to trigger tumorigenic cell transformation, which required additional factors. Tat may provide the additional required oncogenic stimuli for HPV-associated pathogenesis in $\mathrm{HIV}^{+}$individuals. To test this hypothesis, we established human oral keratinocytes harboring HPV-16 genome (HOK-16B) to which Tat was stably introduced by retroviral infection. Tat enhanced the expression of HPV E6 and E7 in HOK-16B and caused enhanced proliferation in the presence of high calcium level. Also, HOK-16B cells formed cystic nodules when injected into nude mice, and Tat-expression led to increased proliferation of these cells in vivo. Our study suggests that HIV may have a direct role in HPV-associated pathogenesis via Tat protein.

\section{Materials and methods}

Cell culture and retroviral infection. HOK-16B cells were cultured in KGM as described previously (26). Retroviruses expressing Tat86 (RV-Tat) were constructed from pLEGFP$\mathrm{Tat}_{86}$, which was kindly provided by Dr F. Peruzzi (Center for Neurovirology and Cancer Biology, Temple University, Philadelphia, PA). The retroviral expression plasmids were transfected into GP2-293 universal packaging cells (Clonetech, Mountain View, CA) with pVSV-G envelope plasmid using a calcium-phosphate transfection kit (Invitrogen, Carlsbad, CA). Two days after transfection, the virus supernatant was collected and concentrated by ultracentrifugation. The virus pellet was resuspended in KGM and was used for infection or stored in $-80^{\circ} \mathrm{C}$ for later use. $\mathrm{HOK}-16 \mathrm{~B}$ were infected with $\mathrm{RV}$-Tat in the presence of $8 \mu \mathrm{g} / \mathrm{ml}$ polybrene (Sigma, St. Louis, MO) for $3 \mathrm{~h}$, and maintained in serial subcultures.

Reverse transcription (RT)-PCR. Total RNA was isolated from the cultured cells using TRIzol ${ }^{\mathrm{TM}}$ reagent (Invitrogen) and was subjected to RNases-free DNase I digestion at $37^{\circ} \mathrm{C}$ for $2 \mathrm{~h}$ to eliminate any contaminating genomic DNA. DNA-free total RNA $(5 \mu \mathrm{g})$ was dissolved in $15 \mu 1$ DEPC- $\mathrm{H}_{2} \mathrm{O}$, and the RT reaction was performed in first strand buffer (Invitrogen) containing $300 \mathrm{U}$ SuperScript II (Invitrogen), $10 \mathrm{mM}$ dithiotreitol, $0.5 \mu \mathrm{g}$ random hexamer (Promega Corp., Madison, $\mathrm{WI})$ and $125 \mu \mathrm{M}$ dNTP. The annealing reaction was carried out for $5 \mathrm{~min}$ at $65^{\circ} \mathrm{C}$, and cDNA synthesis was performed for $2 \mathrm{~h}$ at $37^{\circ} \mathrm{C}$, followed by incubation for $15 \mathrm{~min}$ at $70^{\circ} \mathrm{C}$ to stop the enzyme reaction. The RT product was diluted with $70 \mu 1 \mathrm{H}_{2} \mathrm{O}$.

The following primers were used for PCR amplification: E6 primers, 5'-ATGTTTCAGGACCCACAG-3' (forward), 5'-CAGGACACAGTGGCTTTT-3' (reverse); E7 primers, 5'-GATCGGATCCATGCATGGAGATACA-3' (forward), 5'-CTAGGTCGACTTATGGTTTCTGAGA-3' (reverse); and Tat primers, 5'-GATCGTTAACATGGAGCCAGTAGAT-3' (forward), 5'-TCAGGGATCCTTACTGCTTTGATAG-3' (Reverse).

Analysis of Tat-responsive LTR reporter activity. The following reagents were obtained through the NIH AIDS Research and Reference Reagent Program, Division of AIDS, NIAID, NIH: pBlue3'LTR-luc from Drs Reink Jeeninga and Ben Berkhout. Approximately $5 \times 10^{4}$ cells per well was plate onto 6-well plates and incubated $24 \mathrm{~h}$ before transfection. The pBlue3'LTR-luc plasmid ( $1 \mu \mathrm{g} /$ well) was transfected for $6 \mathrm{~h}$. pRL-SV40 plasmid (0.001 $\mu \mathrm{g} /$ well), which has the Renilla luciferase gene under the transcriptional control of SV40 enhancer/promoter, was co-transfected to normalize the activities shown by the pBlue3'LTR plasmid. Cells were collected $48 \mathrm{~h}$ after transfection, and the cell lysates were prepared using DualLuciferase Reporter Assay System (Promega). The luciferase activity was measured using a luminometer.

Western blotting. Whole cell extracts (WCE) from HOK-16B cells expressing Tat $_{86}$ were fractionated by SDS-polyacrylamide gel electrophoresis (PAGE) and transferred to Immobilon protein membrane (Millipore, Billerica, MA). Immobilized membrane was incubated with primary antibodies, i.e., Tat (BH10; NIH AIDS Research and Reference Reagent Program) and B-actin (I-19, Santa-Cruz Biotechnology Inc., Santa-Cruz, CA), and probed with the respective HRP-conjugated secondary antibodies. Chemiluminesent signals were detected using ChemiDoc System (Bio-Rad, Hercules, CA). The following reagents were obtained through the NIH AIDS Research and Reference Reagent Program, Division of AIDS, NIAID, NIH: HIV- $1_{\mathrm{BH} 10}$ Tat monoclonal antibody (15.1).

Determination of tumorigenicity in vivo. Tat-expressing HOK-16B cells $\left(0.5 \times 10^{7}-1.0 \times 10^{7}\right)$ were collected and injected subcutaneously into the flank of immunocompromised mice (strain nu/nu, Charles River Laboratories, Wilmington, MA). The animal study was done according to the protocol approved by the Animal Research Committee at UCLA. The kinetics of tumor growth was determined by measuring the volume in three axes of the nodules using calipers. The efficiency of tumor formation per each tested cell type was determined by the number of the mice (of the total number of mice injected) bearing palpable tumors exceeding $300 \mathrm{~mm}^{3}$ after 22-30 days post-injection.

Immunohistochemical staining in paraffin-embedded tissues from nude mice. The masses from the nude mice were collected and processed at the Translational Pathology Core Laboratory (TPCL), David Geffen School of Medicine at UCLA. Paraffinembedded tissue samples were sectioned at $4 \mu \mathrm{m}$, and immunohistochemical staining was performed with antiKi-67 antibody (C-20; Santa Cruz Biotechnology, Inc.) at 1:100 dilution as described previously (27). The samples were counterstained with hematoxylin.

\section{Results}

Viral expression of exogenous Tat in HOK-16B cells. To investigate the oncogenic potential of Tat in HPV-harboring 

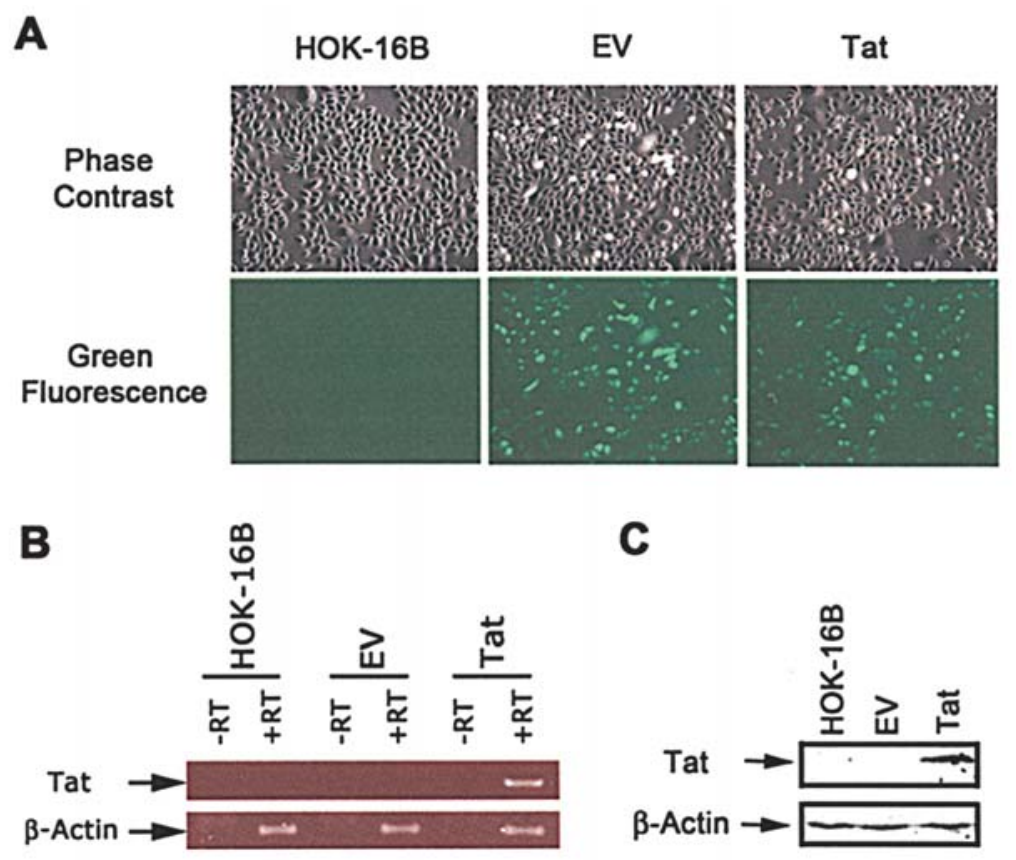

Figure 1. The expression of Tat and its transactivational activity in HOK-16B cells. Human oral keratinocytes immortalized with HPV-16 genome (HOK-16B) were stably infected with retroviruses capable of expressing HIV-1 Tat (Tat). The parental HOK-16B and empty-vector harboring HOK-16B (EV) were also included as controls. (A) Infection was observed under the green fluorescence (magnification x100). (B) The semi-quantitative RT-PCR was performed with or without reverse transcriptase in HOK-16B, EV, and Tat cells. B-ctin was used as a internal control. (C) Western blotting was performed to confirm the physical presence of Tat. $\beta$-actin was used as a loading control.

cells, we used HOK-16B containing the HPV type-16 genome. These cells were stably infected with the retroviral vector expressing the empty vector (EV) or HIV Tat (RV-Tat), and the cells were named as HOK-16B/EV or HOK-16B/Tat, respectively. Four days after infection, the physical presence of Tat protein in HOK-16B/Tat cells was confirmed with green fluorescence reflecting expression of Tat (Fig. 1A). We also used semi-quantitative RT-PCR and the Western blotting to confirm the presence of Tat (Fig. 1B and C).

We next subcloned EV- and Tat-expressing cells and examined the biological activity of Tat using the luciferase reporter gene under the control of HIV long terminal repeat (LTR) promoter. HOK-16B, EV-1 and EV-2, and the clones infected with Tat virus (Tat-1, $-2,-3,-4$, and -5) were transfected with pBlue3'LTR-Luc. The cells were harvested at $36 \mathrm{~h}$ after transfection, and the luciferase activity was measured. The LTR promoter activity was induced by 5-10-fold in HOK-16B cells with Tat expression, while those cells stably infected with EV showed a similar level of luciferase activity as the parental cells (Fig. 2).

The enhanced expression of HPV-16 E6 and E7 in the presence of HIV-1 Tat. Tat is known to enhance the expression levels of HPV-E6 and E7 $(28,29)$, but its effect on HPV-harboring HOK is unknown. To examine whether Tat also enhances the expressions of E6 and E7 in HOK-16B, we performed semi-quantitative RT-PCR. We found that the expressions of E6 and E7 were enhanced in both selected clones of HOK-16B/Tat cells (Fig. 3), indicating that Tat can also enhance the expressions of E6 and E7 in HOK-16B.

Proliferative potential of Tat-expressing $\mathrm{HOK}-16 \mathrm{~B}$ cells in the presence of physiological calcium level. Our previous

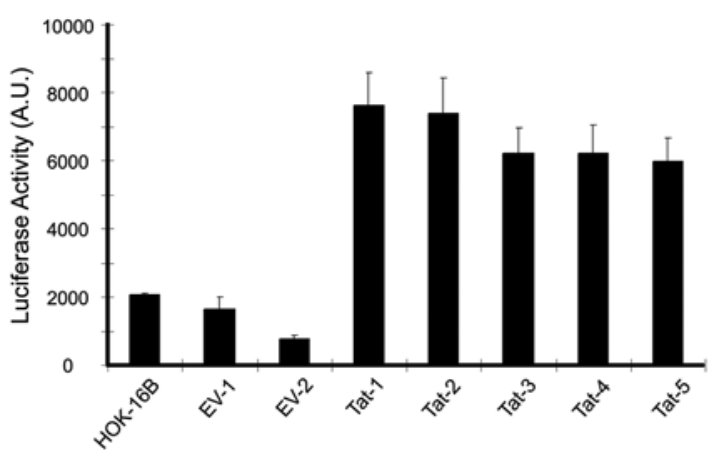

Figure 2. Tat-responsive LTR luciferase activity in the presence of HIV-1 Tat. HOK-16B/EV and HOK-16B/Tat cells were subcloned and subjected to Tat-responsive LTR-luciferase assay to determine the biological activity of Tat. pRL-SV40 plasmid was co-transfected to minimize the transfection variation. The experiment was performed in triplicates to determine the standard deviation.

study showed that NHOK and HOK-16B can maintain their replicative capacity in KGM but not in Dulbecco's modified essential medium (DMEM) containing $10 \%$ bovine serum and physiological level (1.5 mM) of calcium (30). To determine whether Tat confers the cells ability to replicate in the DMEMbased medium, we cultured the HOK-16B/EV or HOK$16 \mathrm{~B} /$ Tat cells in DMEM $+10 \%$ bovine serum and $400 \mu \mathrm{M}$ hydrocortisone (Fig. 4). As expected, the HOK-16B/EV cells showed only limited replication in the DMEM-based medium for five days in culture. However, HOK-16B/Tat cells continued to replicate in DMEM without showing signs of keratinocyte differentiation or cell death and almost reached confluence. These results indicate that Tat elicits phenotypic alteration in HPV-immortalized HOK. 
A

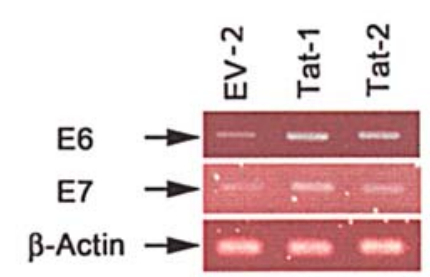

B

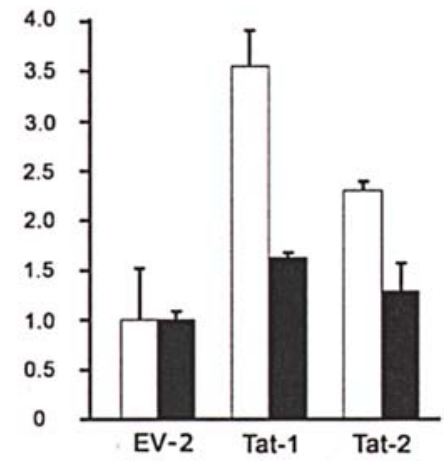

Figure 3. The expression of HPV-16 E6 and E7 in Tat-expressing HOK-16B cells. (A) The expressions of HPV-16 E6 and E7 were determined using the semi-quantitative RT-PCR in the EV-2 clone and two selected clones from Tat-expressing HOK-16B (Tat-1 and Tat-2). B-actin was used as an internal control. (B) Densitometry analysis was performed in duplicates using Scion Image.

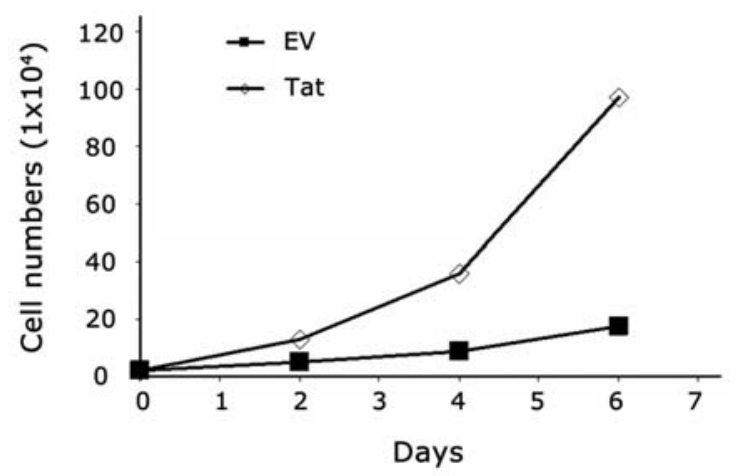

Figure 4. The proliferative potential of Tat-expressing HOK-16B cells in the presence of serum and calcium. Proliferation curve was obtained by plating HOK-16B/EV or HOK-16B/Tat cells (EV-2 and Tat-1) at the density of $1 \times 10^{4}$ cells/well in 6-well plates in the presence of $10 \%$ bovine serum and $1.5 \mathrm{mM}$ calcium. Cells were trypsinized every other days, and cell numbers were obtained using a hemacytometer.

The proliferative potential of Tat-expressing $\mathrm{HOK}-16 \mathrm{~B}$ cells in nude mice. HOK-16B is not tumorigenic in nude mice (30). To examine whether Tat can confer tumorigenic potential of these cells, we injected $1 \times 10^{7}$ cells of $\mathrm{HOK}-16 \mathrm{~B} / \mathrm{EV}$ or HOK-16B/Tat into nude mice. A tumorigenic cell line, HOK-16B BapT, was included as a positive control. As expected, all (3/3) mice harboring $\mathrm{HOK}-16 \mathrm{~B} / \mathrm{EV}$ cells failed to produce nodules when 3 out of 3 mice harboring HOK-16B BapT cells developed tumors (Fig. 5A). The mice injected with HOK-16B/Tat cells formed palpable nodules albeit smaller than those of the HOK-16B BapT cells. Histological examination revealed solid tumor mass formed by the HOK$16 \mathrm{~B}$ BaP-T cells and non-tumorigenic cystic nodules formed
A

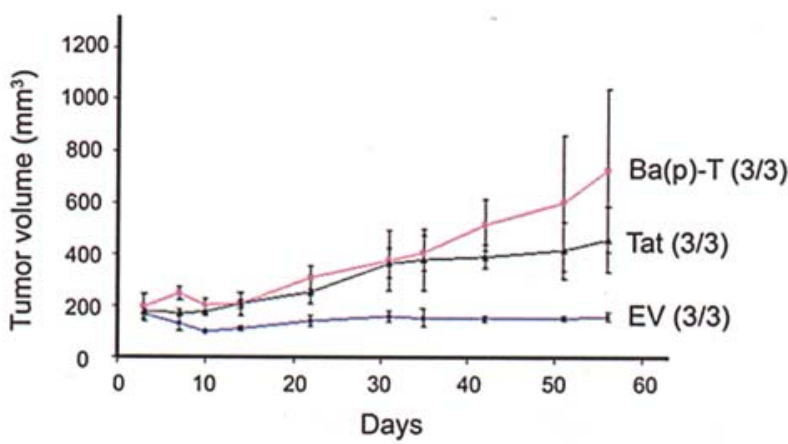

B

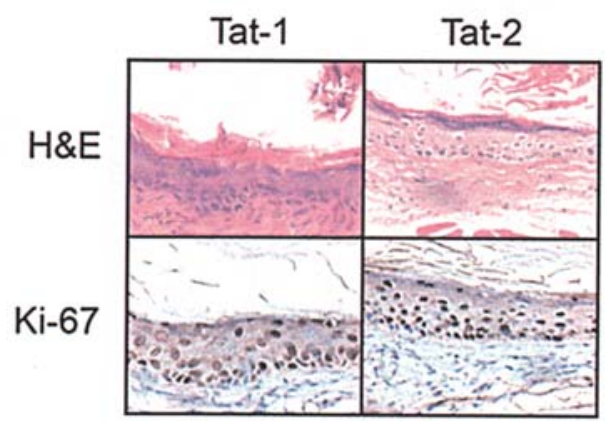

Figure 5. The proliferative potential of Tat-expressing HOK-16B cells in the nude mice. (A) HOK-16B/EV or HOK-16B/Tat cells were injected into the flank of nude mice at $1 \times 10^{7}$ cells/mouse. HOK-16B BapT was included as a positive control. The sizes of the masses were measured up to 2 months. (B) The mice were sacrificed to obtain the masses, and the masses were fixed, paraffin-embedded, and stained for H\&E. Ki67 was also stained. Tat-1 and Tat-2 represent two cystic nodules isolated from two independent mice. Pictures were taken at magnification $\times 100$.

by HOK-16B/Tat cells. When immunohistochemical staining was performed against Ki-67, a marker for proliferation, HOK-16B/Tat cells exhibited strong staining patterns (Fig. 5B), indicating Tat enhances proliferative potential in vivo.

\section{Discussion}

HIV Tat plays a direct role in the tumor pathogenesis of HIV although its role in HPV-associated oral lesions including oral cancers is unknown. Our study showed that Tat enhanced the proliferation capacity of HOK-16B in vitro and in vivo. We confirmed the presence of functional Tat protein in HOK-16B cells after viral transduction of Tat (Figs. 1 and 2). Tat also enhanced the expression of HPV-16 E6 and E7 in HOK-16B cells (Fig. 3), which also acquired the proliferative capacity in high calcium condition (Fig. 4) and in nude mice (Fig. 5). These results suggest that HIV may contribute to the pathogenesis of HPV through Tat.

A higher prevalence of oral HPV infection in $\mathrm{HIV}^{+}$ individuals is evident as demonstrated by several research groups $(31,32)$. The majority of HPV genotypes detected in the oral cavity of $\mathrm{HIV}^{+}$individuals were 'high-risk' HPVs, particularly type-16, which is associated with head and neck, anal, and cervical tumors (33-35). Therefore, our finding that Tat enhances the expression of HPV-16 E6 and E7 is physiologically significant.

Tat has been shown to have oncogenic properties and contributed to the HIV-associated tumor pathogenesis. Tat 
inhibits p53 tumor suppressor, both at the level of p53 gene expression and protein acetylation $(19,21)$. Likewise, Tat physically interacts with RB2/p130 tumor suppressor protein through the pocket region, resulting in the loss of cell cycle check-point and uncontrolled cell proliferation (20). The most direct evidence to support the oncogenic potential of Tat was shown using the Tat-transgenic (TT) mice, which were constructed using recombinant DNA containing BK virus early region and HIV Tat under the control of HIV LTR promoter-enhancer (23). Among the 171 TT mice examined, $29.2 \%(50 / 171)$ showed spontaneous tumor development, while only $3.7 \%(15 / 400)$ control mice showed tumor development. In addition, the transgenic mice also showed significantly higher incidences of non-tumorigenic lesions, such as focal hyperplasia, dysplastic lesions, polyps, cysts, and liver diseases, compared with the controls (23). Consistent with these previous reports, our study also showed formation of cystic nodules by HOK-16B/Tat cells when injected in nude mice, and that Tat expression led to increased proliferation of cells within the cystic epithelium.

The relationship between HIV and HPV in oral cancers is not as definitely established as in anal/cervical cancers despite the fact that the inner linings of the oral cavity and cervix/anal canal are composed of stratified squamous epithelium, for which HPV exhibits natural tropism. One possible difficulty in establishing the relationship between HIV and HPV-associated oral cancers is the poor demonstration of consistent expression of the HPV E6 and E7 proteins, which are essential oncogenic proteins for transformation (36). The potential still exists for the occurrence of HPV-associated malignant oral lesions, especially with long-term treatment of HAART and subsequent increased lifespan of $\mathrm{HIV}^{+}$ individuals. Therefore, implementing routine screening and preventive vaccination against $\mathrm{HPV}$ in $\mathrm{HIV}^{+}$individuals should be carefully considered in the era of HAART.

\section{Acknowledgements}

This work was supported in part by grants DE014147 (N.-H.P.), DE018295 (M.K.K.), and DE017121 (R.H.K.).

\section{References}

1. Piketty $\mathrm{C}$ and Kazatchkine MD: Human papillomavirus-related cervical and anal disease in HIV-infected individuals in the era of highly active antiretroviral therapy. Curr HIV/AIDS Rep 2: 140-145, 2005.

2. Hodgson TA, Greenspan D and Greenspan JS: Oral lesions of HIV disease and HAART in industrialized countries. Adv Dent Res 19: 57-62, 2006.

3. Palefsky JM: Cervical human papillomavirus infection and cervical intraepithelial neoplasia in women positive for human immunodeficiency virus in the era of highly active antiretroviral therapy. Curr Opin Oncol 15: 382-388, 2003.

4. Piketty C, Darragh TM, Da Costa M, Bruneval P, Heard I, Kazatchkine MD and Palefsky JM: High prevalence of anal human papillomavirus infection and anal cancer precursors among HIV-infected persons in the absence of anal intercourse. Ann Intern Med 138: 453-459, 2003.

5. Flaitz CM, Nichols CM, Adler-Storthz K and Hicks MJ: Intraoral squamous cell carcinoma in human immunodeficiency virus infection. A clinicopathologic study. Oral Surg Oral Med Oral Pathol Oral Radiol Endod 80: 55-62, 1995.

6. Anil S, Beena VT and Nair RG: Squamous cell carcinoma of the gingiva in an HIV-positive patient: a case report. Dent Update 23: 424-425, 1996.
7. Van der Waal I: Some unusual oral lesions in HIV infection: comments on the current classification. Oral Dis 3: S197-S199, 1997.

8. Piattelli A, Rubini C, Fioroni M and Iezzi T: Warty carcinoma of the oral mucosa in an $\mathrm{HIV}^{+}$patient. Oral Oncol 37: 665-667, 2001.

9. Casariego Z, Micinquevich S and Gomez MA: HPV in "carcinoma in situ' associated with HIV/AIDS infection: a case report. Med Oral 7: 84-88, 2002.

10. Levi JE, Fernandes S, Tateno AF, Motta E, Lima LP, Eluf-Neto J and Pannuti CS: Presence of multiple human papillomavirus types in cervical samples from HIV-infected women. Gynecol Oncol 92: 225-231, 2004

11. Dayton AI, Sodroski JG, Rosen CA, Goh WC and Haseltine WA: The trans-activator gene of the human $\mathrm{T}$ cell lymphotropic virus type III is required for replication. Cell 44: 941-947, 1986.

12. Jones KA and Peterlin BM: Control of RNA initiation and elongation at the HIV-1 promoter. Annu Rev Biochem 63: 717-743, 1994.

13. Kuppuswamy M, Subramanian T, Srinivasan A and Chinnadurai G: Multiple functional domains of Tat, the transactivator of HIV-1, defined by mutational analysis. Nucleic Acids Res 17: 3551-3561, 1989.

14. Vives E, Brodin P and Lebleu B: A truncated HIV-1 tat protein basic domain rapicly translocates through the plasma membrane and accumulates in the cell nucleus. J Biol Chem 272: 16010-16017, 1997.

15. Jeang KT, Xiao H and Rich EA: Multifaceted activities of the HIV-1 transactivator of transcription, Tat. J Biol Chem 274: 28837-28840, 1999

16. Ott M, Emiliani S, Van Lint C, Herbein G, Lovett J, Chirmule N, McCloskey T, Pahwa S and Verdin E: Immune hyperactivation of HIV-1-infected T cells mediated by Tat and the CD28 pathway. Science 275: 1481-1485, 1997.

17. Westendorp MO, Shatrov VA, Schulze-Osthoff K, Frank R, Kraft M, Los M, Krammer PH, Droge W and Lehmann V: HIV-1 Tat potentiates TNF-induced NF-kappa B activation and cytotoxicity by altering the cellular redox state. EMBO J 14: $546-554,1995$.

18. Wu Y and Marsh JW: Selective transcription and modulation of resting T cell activity by preintegrated HIV DNA. Science 24 : 1503-1506, 2001

19. Li CJ, Wang C, Friedman DJ and Pardee AB: Reciprocal modulations between p53 and Tat of human immunodeficiency virus type 1. Proc Natl Acad Sci USA 92: 5461-5464, 1995.

20. Lazzi S, Bellan C, De Falco G, Cinti C, Ferrari F, Nyongo A, Claudio PP, Tosi GM, Vatti R, Gloghini A, Carbone A, Giordano A, Leoncini L and Tosi P: Expression of RB2/p130 tumor-suppressor gene in AIDS-related non-Hodgkin's lymphomas: implications for disease pathogenesis. Hum Pathol 33: 723-731, 2002.

21. Harrod R, Nacsa J, Van Lint C, Hansen J, Karpova T, McNally J and Franchini G: Human immunodeficiency virus type-1 Tat/ Co-activator acetyltransferase interactions inhibit p53Lys-320 acetylation and p53-responsive transcription. J Biol Chem 278: 12310-12318, 2003

22. Clark E, Santiago F, Deng L, Chong S, De La Fuente C, Wang L, Fu P, Stein D, Denny T, Lanka V, Mazafari F, Okamoto T and Kashanchi F: Loss of G(1)/S checkpoint in human immunodeficiency virus type 1-infected cells is associated with a lack of cyclin-dependent kinase inhibitor p21/Waf1. J Virol 74: 5040-5052, 2000.

23. Altavilla G, Trabanelli C, Merlin M, Caputo A, Lanfredi M, Barbanti-Brodano $G$ and Corallini A: Morphological, histochemical, immunohistochemical, and ultrastructural characterization of tumors and dysplastic and non-neoplastic lesions arising in BK virus/tat transgenic mice. Am J Pathol 154: 1231-1244, 1999.

24. Altavilla G, Caputo A, Lanfredi M, Piola C, Barbanti-Brodano G and Corallini A: Enhancement of chemical hepatocarcinogenesis by the HIV-1 tat gene. Am J Pathol 157: 1081-1089, 2000 .

25. Kang MK and Park N-H: Conversion of normal to malignant phenotype: telomere shortening, telomerase activation, and genomic instability during immortalization of human oral keratinocytes. Crit Rev Oral Biol Med 12: 38-54, 2001.

26. Park N-H, Min B-M, Li S-L, Huang MZ, Cherrick HM and Doniger J: Immortalization of normal human oral keratinocytes with type 16 human papillomavirus. Carcinogenesis 12 : 1627-1631, 1991. 
27. Shin KH, Kang MK, Kim RH, Christensen R and Park NH: Heterogeneous nuclear ribonucleoprotein $\mathrm{G}$ shows tumor suppressive effect against oral squamous cell carcinoma cells. Clin Cancer Res 15: 3222-3228, 2006.

28. Tornesello ML, Buonaguro FM, Beth-Giraldo E and Giraldo G: Human immunodeficiency virus type 1 tat gene enhances human papillomavirus early gene expression. Intervirology 36 : 57-64, 1993.

29. Vernon SD, Zaki SR and Reeves WC: Localization of HIV-1 to human papillomavirus associated cervical lesions. Lancet 344 : 954-955, 1994.

30. Park N-H, Gujuluva CN, Baek JH, Cherrick HM, Shin KH and Min BM: Combined oral carcinogenicity of HPV-16 and benzo(a)pyrene: an in vitro multistep carcinogenesis model. Oncogene 10: 2145-2153, 1995.

31. Coutlee F, Trottier AM, Ghattas G, Leduc R, Toma E, Sanche G, Rodrigues I, Turmel B, Allaire G and Ghadirian P: Risk factors for oral human papillomavirus in adults infected and not infected with human immunodeficiency virus. Sex Transm Dis 24: 23-31, 1997.
32. Kreimer AR, Alberg AJ, Daneil R, Gravitt PE, Viscidi R, Garrett EW, Shah KV and Gillison ML: Oral human papillomavirus infection in adults is associated with sexual behavior and HIV serostatus. J Infect Dis 189: 686-698, 2004.

33. Syrjanen S: Human papillomavirus (HPV) in head and neck cancer. J Clin Virol 32: S59-S66, 2005.

34. Walboomers JM, Jacobs MV, Manos MM, Bosch FX, Kummer JA, Shah KV, Snijders PJ, Peto J, Meijer CJ and Munoz N: Human papillomavirus is a necessary cause of invasive cervical cancer Worldwide. J Pathol 189: 12-19, 1999.

35. Chin-Hong PV and Palefsky JM: Human papillomavirus anogenital disease in HIV-infected individuals. Dermatol Ther 18: 67-76, 2005

36. Hille JJ, Webster-Cyriaque J, Palefski JM and Raab-Traub N: Mechanisms of expression of HHV8, EBV and HPV in selected HIV-associated oral lesions. Oral Dis 8: 161-168, 2002. 